\title{
Code camps and hackathons in education - literature review and lessons learned
}

\author{
Jari Porras \\ Lappeenranta Univ. of Tech. \\ Jari.Porras@lut.fi \\ Ari Happonen \\ Lappeenranta Univ. of Tech. \\ Ari.Happonen@lut.fi
}

\author{
Antti Knutas \\ Lappeenranta Univ. of Tech. \\ Antti.Knutas@lut.fi \\ Jayden Khakurel \\ Lappeenranta Univ. of Tech. \\ Jayden.Khakurel@lut.fi
}

\author{
Jouni Ikonen \\ Lappeenranta Univ. of Tech. \\ Jouni.Ikonen@lut.fi \\ Antti Herala \\ Lappeenranta Univ. of Tech. \\ Antti.Herala@lut.fi
}

\begin{abstract}
Motivation: Code camps and hackathons been used in education for almost two decades. These approaches are usually intensive and for most times quite practical events for solving some real-world problems with various educational objectives. The objectives and structures of these events differ depending on the role of the event in curricula.

Problem statement: Both code camps and hackathons been implemented in various ways, with varying success levels. As expected the implementation of the event varies considerably depending on the objectives set for the event, but that then leads to the difficulty and problem setting to understand what organizing of these events actually mean. For educational context, curricula have also its role in defining the targeted skills and competencies the events has to consider too.

Approach: We applied a systematic literature review (SLR) to look at the various definitions and modes of these events. Whether it is called "code camp", or "hackathon", or anything else with the same basic meaning, we want to find out what skills and competencies these events emphasize, how they are used in Computer Science (CS) and Software Engineering (SE) education and what are the general structures of the actual arranged events.

Contribution: It is aim of this SLR to i) identify various possible ways of implementing these intensive events, and ii) reflect the results to the lessons we have learned of almost two decades of various intensive code camps and hackathons we have been organizing building and participating into. Based on the results, we claim that there is tremendous potential of using these events in education and in the curriculum than how it has been applied so far.
\end{abstract}

\section{Introduction}

Practical tasks and applying the knowledge acquired from lectures has been emphasized during the few last years. Both the students and the higher education institutes (HEI) share the challenges of rapidly evolving demands for the knowledge, skills and competencies. Teachers have constant challenges of keeping themselves well educated about the newest standards, tools, frameworks and languages implemented and used by the industry. On the other hand, students crave for more soft skills as that is something they immediately face when they go to their first summer jobs and later on when they start their careers after graduation. For HEIs the added challenge comes from the fact, that the software engineering itself is increasingly interdisciplinary by its nature [1]. At the same time big data, data-analysis, computational sciences, digitalization and social media etc. are having growing role in software engineering (SE) and computer science (CS) curricula [2]. The combination of the expanding set of technologies and evolving needs for (real work life) soft skills makes the SE / CS education challenging. HEIs need new ways of emphasizing this evolving skill set.

Skills that are needed in the real work life are practiced in many practice-oriented courses, such as capstones or code camps and hackathons. Several papers on capstone implementations have been published (e.g. [3], [4], [5] were presented in the 2017 conference on software engineering education) and capstones seem to be the approach for connecting students to real projects [1], [2]. On the other hand code camps and hackathons and their role in this skill acquirement has not been discussed so much although they are highly appreciated way of learning new algorithms, languages, technologies in software engineering education context. These courses are naturally intensive collaborative courses teaching students teamwork, time pressure management, project organization and task sharing among the technical skills they will need after graduation.

The rest of this paper is structured as follows. Following this motivation to the topic chapter 2 presents the methodology used in this research, i.e. 
Systematic Literature Review. We present the objective of the research and process that was applied to achieve that objective. We have formulated 4 research questions into which we wanted to get the answers by using the literature review. Chapter 3 presents the results of our literature review which answers the research questions based on the analysis of the selected literature. Chapter 4 discusses the findings and our reflections to these findings. Chapter 5 concludes our paper.

\section{Methodology and research questions}

This paper uses systematic literature review, as presented by Kitchenham et al. in [6], [7] to find out the current state of the art in using code camps and hackathons in software engineering and computer science education to see how these intensive events can help in achieving the skills and competencies needed in real work life.

The steps adapted for the review process, are listed as follows:

1. Define the research questions based on the objectives of the research.

2. Define search queries based on the research questions. Finding proper search queries (terms) might require an iterative process. Tools i.e. NAILS $^{1}$ [8] have been be used for the first iterations.

3. Search articles on primary studies using search strings on scientific libraries and databases. This research used Web of Science ${ }^{2}$ for gathering the articles.

4. Screen the initial set of articles by applying inclusion and exclusion criteria to determine whether each potential article should be included or excluded from this study. Inclusion and exclusion happen in multiple stages, starting from the screening of titles and abstracts and ending to the analysis of the whole document. Secondary articles can be added by manually browsing cited articles in the selected set of primary articles.

5. Extract the predefined set of data from the selected set of articles.

6. Analyse the extracted data to answer the research questions. Various tools exist for the analysis, such as HAMMER ${ }^{3}, \mathrm{KHCode}^{4}$ or VOSviewer ${ }^{5}$.

7. Present the acquired results

\footnotetext{
${ }^{1}$ nailsproject.net

${ }^{2}$ webofknowledge.com

${ }^{3}$ hammer.nailsproject.net

${ }^{4}$ khc.sourceforge.net

${ }^{5}$ vosviewer.com
}

\subsection{Research objective and research questions}

As code camps and hackathons have been used for various purposes for almost two decades (first ones are from 1999 related to open source software development and hacking marathons [9], [10]) we wanted to find out if they have been actually used in education and if so, how they have been implemented. Implementation, as such, includes the event structure and facilitation practices, intended learning outcomes and the reference of the event to the curricula, if available. Following the determination of need, RQs based on the objectives of the study were formulated [11], as presented below:

RQ1: How are the code camps and hackathons defined in the literature?

Rationale: As these short term intensive events have many names and ways of arranging we first look at the definitions of these events to see if these names mean different things in these implementations and are the differences subtle or notable.

\section{RQ2: What kind of educational structures have been used in code camps and hackathons?}

Rationale: These events come in different lengths, they contain multitude of different kind of stage holders and events are arranged in different formats and as such we wanted to study how these events have been practically build to accommodate the different needs.

RQ3: What skills and competencies have been emphasized in the code camps and hackathons presented in literature?

Rationale: Each and every educational activity will have some skills and competencies emphasized. Through the literature review we study the various skills and competencies emphasized with the events.

RQ4: How code camps and hackathons have been used in SE and CS education?

Rationale: We wanted to study if these events have been included as a part of curricula and how widely or if they are provided just for an extra activity for the students.

\subsection{Search queries and inclusion/exclusion criteria}

We used Web of Science database as our main source for finding out the research articles. Web of Science indexes the main databases and provides a comprehensive view to the publications. As our 
research objective and research questions were emphasizing both the definition and the education part we decided to look at them separately, meaning that terms "Definition" and "Education" were used in different searches. Definition was looked for both Code Camps and Hackathons by using them in the same query. The "Education" part was searched separately for "Hackathon" and "Code camp" as based on the first searches the combined search provided a large set of non-related papers. "Code camp" related searches were done in the end by not using the "Education" as the combined search provided only few matches. All database searches were implemented in May 2018 with no special restrictions on domain or publication year. The search led to 145 articles (see Table 1). 21 papers had both "Definition" and "Education" datasets thus after removal 124 papers were selected for further analysis.

Table 1. Literature review queries and the number of papers.

\begin{tabular}{|l|c|c|l}
\hline Search queries & $\begin{array}{c}\text { Found } \\
\text { papers }\end{array}$ & $\begin{array}{l}\text { Without } \\
\text { replicates }\end{array}$ & $\begin{array}{l}\text { Included papers in th } \\
\text { final dataset }\end{array}$ \\
\hline $\begin{array}{l}\text { "Hackathon" OR } \\
\text { "Code camp" and } \\
\text { "Definition" }\end{array}$ & 115 & 94 & $\begin{array}{l}33 \text { (EC2 - 10 papers } \\
\text { EC3 - 51 papers) }\end{array}$ \\
\hline $\begin{array}{l}\text { "Hackathon" AND } \\
\text { "Education" }\end{array}$ & 21 & 21 & $\begin{array}{l}11 \text { (EC1 - 1 paper, EC2 } \\
\text { papers, EC3 - } \\
\text { papers })\end{array}$ \\
\hline "Code camp" & 9 & 9 & $7(2$ of EC3)) \\
\hline \hline $\begin{array}{l}\text { Total number of } \\
\text { papers }\end{array}$ & 145 & 124 & 51 \\
\hline
\end{tabular}

The selected (i.e. 124 papers) were read through for content analysis inclusion check. The first author did the main part of this analysis with the idea that the paper had to describe an implementation of a code camp or hackathon event (Inclusion criteria 1) in order to be included into the final set of papers. Papers were excluded from the literature review if a) they were not in English language (Exclusion criteria 1 - 1 paper), b) they were not accessible (Exclusion criteria 2 - 16 papers) or they did not describe a code camp or hackathon event (Exclusion criteria 3 - 56 papers). Total of 51 papers were included into the final dataset.

\subsection{Data collection and analysis}

A template was created to register the relevant information from the final set of 51 reviewed papers. The data extraction process included the following input from each selected paper: Basic information: ID, Author(s), Year of Publication, Title, Publication type (workshop, conference, journal), Keywords, Abstract; Specific information: Definition (RQ1),
Length of the event (demographics), Participants (demographics), Number of participants (demographics), Structure of the event (RQ2), Targeted learning outcomes - skills and competencies (RQ3), How the event is tied to education (RQ4), Event domain (demographics), Other issues. Basic information is used for identifying various papers while specific information intends to answer to the research questions of this study. Further, additional information about the events were collected for demographics purposes.

Data was analysed with three different tools and approaches. The abstracts of the selected papers (or groups of papers) were submitted to Wordle $^{6}$, KHCoder and Nails ${ }^{7}$. Wordle was used for illustrating the most used words in abstracts. Wordle does not allow deeper analysis of the content. On the other hand, KHCoder enables quantitative content analysis or text mining and it was used for deeper analysis of the contents of the papers. Even a bit deeper goes topic modeling. Topic modeling with a modified version of the Nails software package and the topicmodels library was used to discover themes in the text. After data collection the documents were sorted into topics using the Latent Dirichlet Allocation (LDA) algorithm [12]. LDA can be used as a statistical method text mining method for assigning documents into topics, which are detected using word association and distributions [13]. It is a commonly used method for text analysis and equivalent methods have been used to statistically analyze scientific texts in previous studies [14], [15].

\section{Results}

Results of this literature review are presented by answering to the research questions based on the analysis of the collected data. The analysis of the yearly distribution on number of publications (Figure 1) shows that majority of the papers have been published after 2012 and only 2 papers in 2008. Those two early papers were published by the authors of this publication. Given the fact, that the hackathon as a term has been around since 2000, this finding suggests that the development of the events has been happening outside of research/academic environment and it has taken quite a long time (roughly 10 years) to raise the interest towards educational application of Code Camps/ hackathons, Or, at least has gotten wider popularity only just recently.

\footnotetext{
${ }^{6}$ wordle.net

${ }^{7}$ nailsproject.net
} 


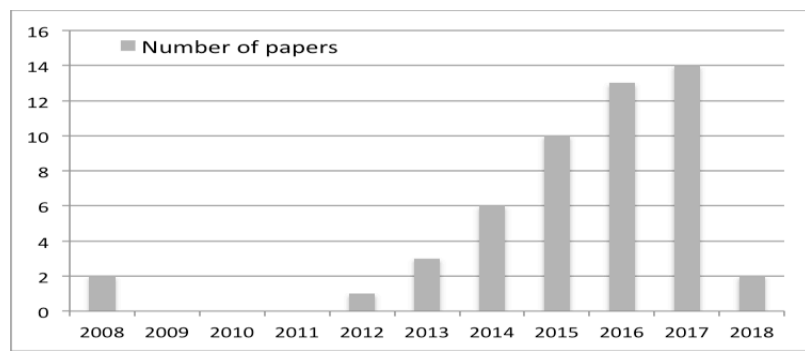

Figure 1. Yearly distribution of the included papers.

\subsection{Defining code camps and hackathons}

Like the search results already showed, as a term in publications, term code camp (7 papers) has not been used so much at all and the term hackathon (44) has actually been used more frequently. With the emphasized word analysis of how these two terms have been defined in the literature (Figure 2 and 3) it seems that both terms in academic sense mean essentially the same thing, namely short time collaborative innovation activity focusing on some use of computer skills. We need to look deeper to the definitions to see the actual differences in the meanings.

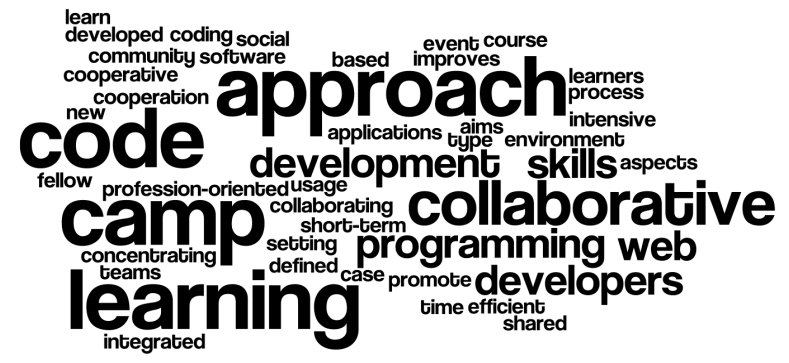

Figure 2. Code camp definition word cloud.

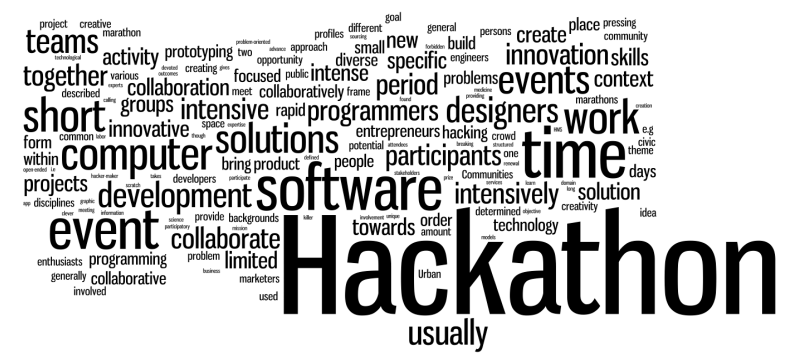

Figure 3. Hackathon definition word cloud.

As for application areas, code camps have been mainly used for computer science or software engineering related practical courses while hackathons are more widely used in business context. One could safely conclude here that term code camp refers to more hard core coding activities like described in [16] "Communities of computer programmer enthusiasts and system designers would gather for 24-hour "hacking marathons" where clever solutions were created or improved" while term hackathon has more wide spread or general meaning when people refer to it. To be little bit more punctual, following definitions will describe where this perceptions of wideness for the term hackathon comes from.

- A hackathon is a sprint computer programming competition where participants collaborate to create software from scratch in intense sessions over one or two days [17].

- Hackathon, which fosters the innovation potential of small focused teams while at the same time not taxing the financial resources of the corporation [18].

- Civic hackathon is a participatory event to prototype innovative services through collaboration between citizens and engineers to address social issues [19].

- Hackathons are alternative meeting formats emphasizing the full participation of everyone [20].

- Hackathon can be a breeding ground for brainstorming, innovation, networking, and product development, and as such they can have multiple outcomes including the sparking of new businesses and entrepreneurial activity [21].

Definitions for the term "Hackathon" emphasize various aspects. In general, hackathons are considered as some sort of competitions with prizes although some papers definitely emphasize the non-competitive approach. Another very used perception for the hackathon is the collaboration with companies, usually implemented in a competition format. These hackathons are often arranged by the companies to crowdsource solutions to challenging problems, to find new potential employees or e.g. to disseminate the company related information. Public stakeholders, e.g. cities and municipalities, have also started using hackathons. In these hackathons, the aim is in public engagement and collaboration between citizens and other stakeholders and in general the goal setting pursues public good goals. As such, hackathons can be seen as a new more intensive meeting ground for skillful mindsets and others with fitting challenges for those minds.

On another side of the fence, academics have used hackathons to create innovations and possible seeds for new businesses. One sign of the wider perception of the term hackathon is the prefixes attached to the term and modifications of the term. There exists civic hackathons [22], [19], datathons [23], [24], semesterathons and summerathons, designathons [25]. These examples show that the term hackathon and the 
approach it represents (i.e. rather intensive way of working) is well understood and applied in different domains. Based on the literature the most common domain (15/51 papers) for hackathons seems to be somehow related to health (e.g. healthcare, medicine, health monitoring and data mining related to healthcare). Other common domains are related to service development for local challenges (e.g. through smart cities, IoT). The emphasis of hackathons is more on either applying IT for other domains or completely forgetting IT and staying in more contextual or business model levels.

As a summary of these terms, we could conclude that although both terms in general emphasize short time interdisciplinary collaborative working it seems that a) term code camp refers to more IT or software oriented events, b) term hackathon has almost completely replaced it although c) term hackathon does not so clearly implicate the focus of the event.

\subsection{Evolution of hackathons}

In order to get an even better perception of the evolution of hackathons based on the selected literature the content of the hackathon related papers were analyzed by KHCoder and Nails. KHCoder, among other things, can reveal how the events were developed during these years. Figure A.1 in Appendix shows the yearly emphasis on hackathons based on the literature. First years of the hackathons were focusing on collaboration (2012), agile development (2013) and software (2014), whereas latest years the have seen the rise of data $(2105-2016,2018)$, healthcare as application domain (2017-2018) and community type of events (2016-2018).

Another perception to the same issues can be seen from topic modeling. Figure A.2 in Appendix shows the groups generated by LDA (general terms shown for all topics). The topic modeling process found four themes when guided by the semantic coherence heuristic [26]. First theme was characterized by the words hackathon, participation, team, and student. Second theme was characterized by the words data, open, user, and civic. Third theme was characterized by the words core, science, data, sample, and network. Fourth theme was characterized by the words health, event, care, hackathon, and medical. First two themes are close to each other but show clear distinction between these groups of papers. Third and fourth themes are further away from these first two and each other. If one would be interested in education related hackathons, one should look more closely to the papers in the first theme of the model.

\subsection{What kind of structures have been used for code camps and hackathons}

Code camps and hackathons have been proposed for different lengths as presented in Table 2. Majority of the presented events are two days (that seems to be the de facto standard for these intensive events as $45 \%$ of found publications refer to that) though shorter and longer events have been proposed (22\% for shorter and around $20 \%$ for $3-5$ days events). Extremely short (i.e. few hours) or long (i.e. weeks) events have been proposed rarely and it remains unclear what makes these code camps or hackathons. In general, they can follow the same general structure of these intensive events but do they really emphasize the same learning outcomes that code camps and hackathons represent? How much do participants engage or interact in a $4 \mathrm{~h}$ or a semester-long hackathon?

Table 2. Lengths of the reported events.

\begin{tabular}{|c|c|c|}
\hline Length & Number of papers & $\begin{array}{c}\text { Share of } \\
\text { publications }\end{array}$ \\
\hline \hline 24h or less & $\begin{array}{c}13 \text { (out of which } 4 \\
\text { less than 12h) }\end{array}$ & $25 \%$ \\
\hline Two days (48h) & 23 & $45 \%$ \\
\hline 3-5 days & 11 & $22 \%$ \\
\hline More than 5 days & 2 & $4 \%$ \\
\hline Not mentioned & 2 & $4 \%$ \\
\hline \hline Total & 51 papers & $100 \%$ \\
\hline
\end{tabular}

The structure of the code camp and hackathon can typically be divided in three parts; pre-event, event and post-event [27]. Pre-event activities might consist of some preparatory activities like reading of background material or pre-lectures [28], idea generation [29] or team building. However, quite often both idea generation and team building are part of the actual event, especially in a themed event in which all teams innovate under the same theme or target setting. Idea generation could happen individually or in small groups that then are pitched to the others (other teams, organizers, customers or other stakeholders) and after that each person may select a team whose idea is closest to own heart. The event itself contains at minimum the collaborative working but often also some themed presentations in the beginning and team demonstrations in the end. Especially in competitionbased events the final demonstrations are evaluated and used for deciding the "winners" (various winning conditions or even categories can be used). Working during the event may vary depending on the type of the event. Many of the events emphasize interdisciplinary collaborative working [30], [31], [32], [28]. In some 
events teams might work in completely different spaces [33] that can strengthen intra-team collaboration but decrease the inter-team collaboration regardless of digital platforms (e.g. Wiki or Slack) available. Of course, other programme can be used to promote the inter-team collaboration. For example, and interesting approach was proposed by [34] to use breakout sessions to create discussions between teams.

As a summary of the structures used in code camps and hackathons, one could emphasize three elements that almost all papers emphasize; collaborative idea generation, inter-disciplinary working and intensive pitching. Collaborative idea generation lets everybody to contribute to the work to be done and it helps all the teams to achieve better end results (by not wasting peoples time to "reinvent the wheel"). Working should always happen in teams with various talents and perceptions as that allows thinking that is more heterogeneous and solutions. Various team sizes (from 2 to close to 10) have been proposed and depends heavily how multidisciplinary approach is used. Finally yet importantly the active pitching of ideas distribute them the best.

\subsection{What skills and competencies have been emphasized}

The organizers of the hackathons defined some sort of pre-defined wishes for the outcomes. These outcomes can be divided into learning outcomes (for more education-oriented events) and practical outcomes (i.e. tangible results of working in the event). Table 3 presents the most emphasized skills and learning outcomes in the selected set of papers. The four most emphasized learning outcomes for the participants in these papers are a) teamwork or collaboration skills, b) creativity or innovation skills, and c) some context specific skill (e.g. Java programming skills) and d) presentation (or discussion) skills.

Table 3. Emphasized skills in the events.

\begin{tabular}{|c|c|c|}
\hline Emphasized skill & Number of papers & $\begin{array}{c}\text { Share of } \\
\text { publications }\end{array}$ \\
\hline \hline $\begin{array}{c}\text { Project, teamwork, } \\
\text { collaboration }\end{array}$ & 22 & $43 \%$ \\
\hline Presentation etc. & 15 & $29 \%$ \\
\hline $\begin{array}{c}\text { Programmin, domain } \\
\text { knowledge }\end{array}$ & 14 & $27 \%$ \\
\hline Innovation, Creativity & 12 & $24 \%$ \\
\hline Business aspects & 7 & $14 \%$ \\
\hline $\begin{array}{c}\text { Critical thinking, } \\
\text { problem solving }\end{array}$ & 5 & $10 \%$ \\
\hline
\end{tabular}

Nevertheless only rarely these learning outcomes are emphasized clearly in the papers [35], [36], [37]. It seems that the focus is more on practical project outcomes than in learning outcomes. Regardless of the actual analysis of the outcomes, all papers of the literature study have a very positive perception towards hackathon. Even though, for many, the event has been the first attempt to use hackathon type of an approach and the results have been promising like presented by the quotes from papers:

"...Plenty of collaboration was observed during the events. Teams were actively encouraged to help each other and as such no competitive behaviors were observed during the events. As an example, the following was observed: If a team had an issue with PHP, for example, they might yell out "is anyone here a PHP guru?" and someone from another team would leave their project for a bit and help with the other project..." [38].

"Team got experience from the other team. Different working style can be brought from the other team if good practices were found." [36].

This is the same behavior we have noticed in the events we have organized. Individuals help each other across the team boundaries. On the other hand, competitive type of event may not show this kind of behavior. We have seen exceptions to this in our event observations, especially when small startups do team up to meet the event goals set by large enterprise.

As a summary of the analysed set of papers, one could claim that most of the code camp events and hackathons do not set clear educational learning outcomes but use the hackathon more like a tool to innovate new solutions in which the solution is more important than the learning at the process of developing the new solution. This is partly due to the approach of using these events as an innovation platform and not as a learning platform. One explaining reason for this could be the perception from literature, that the emphasis on hackathons is more to the stakeholder collaboration side [32], [29], [39]. As all papers point, the approach considered in these events are appropriate for influencing and creating innovations, there is definitely room to extend the work towards the learning aspects. Producing good innovations is not contradictory of learning at the same time but the learning should be emphasized at the event.

\subsection{How code camps and hackathons have been used in SE and CS education}

Surprisingly few papers describe any kind of relationship to education in general or even any special 
course/module concepts. Although many papers involve students of various levels (pre-university [40], undergraduate [41], [27], master level [42], [43], [37] or even phd level [44] it seems that code camps and hackathons are just a new way of working rather than an integral part of the education. For example [25] and [45] clearly show that this is just a new pedagogical approach for teaching.

As the outcomes of the code camp and hackathon events are mostly positive and the approach analysed from different perspectives (e.g. connection to the stakeholders [46], student benefits [41], stakeholder perspectives [38]) there are only few considerations how it could be tied into curriculum. Page et al. [27] gives some thoughts for the curriculum but from the event organizing point or view. Guerrero et al. [46] sees the value of hackathons and compares the learning outcomes to internships and conclude that internships and hackathons emphasize a bit different skill sets and as such both are needed.

As a summary of the analysed papers one could conclude that even though code camps and hackathons are widely used, especially in connection with companies, their use as an integral part of curriculum is immature or at least it has not been properly documented in academic papers. The outcomes of the events are very positive and the events have attracted large amounts of participants but still academics seem hesitant to integrate this mode of courses to their curricula. As the approaches are still quite rare and distinct and one cannot really make any quantitative analysis of these approaches.

\section{Discussion and reflections}

We set 4 research questions to our literature review to see how code camps and hackathons have been and could be used in software engineering and computer science education. Our study (RQ1) i.e. how these two terms (code camp and hackathon) have been used for various types of events revealed that although "hackathon" is the term used mostly today it does not necessarily describe an educational event. Actually, companies and public organizations have adopted this term (hackathon) for various engagement activities. It also represents wide variety of application domains and not necessarily have anything to do with pure SE or CS skills. Term "code camp" has not been used as intensively, as shown by the number of papers published, but it reflects better the SE or CS field. The code camps and hackathons come in different forms and lengths (RQ2) but it seems clear that both event types follow roughly the same structures. In the end, the structure aims at emphasizing the outcomes set for the events. In many cases, hackathons emphasize more of the innovation aspects and as such the final solutions than actual learning (outcomes) that would be of interest of educational events (RQ3). This might be one of the key reasons why code camps and hackathons have not so much been integrated into the curriculum (RQ4). In a certain sense code camps and hackathons can be compared to capstone projects in sense of learning outcomes. Capstones are commonly used in curricula but these intensive events not so much. It could be beneficial to compare these two approaches and their benefits. Based on this literature review it is evident that code camps and hackathons emphasize the team working skills and stakeholder connections, skills that capstones are also emphasizing. If these events emphasize important skills the question remains why don't we use them more in our education?

We have analyzed the threats of validity of this study based on construct, internal and external validity as well as reliability. The construct validity focuses on whether the theoretical constructs and interpreted and measured correctly. In this study we have used a widely used Systematic Literature Review by Kitchenham et al [6], [7] and as such minimized the threats to the construction validity. Internal validity, i.e. study design, follows from the Systematic Literature Review protocol. Furthermore, data mining techniques with quality heuristics were used to support the qualitative review analysis. Two of the authors performed data collection and analysis while two other authors focused on the data analysis. All the collected data were shared with all the authors. The external validity, i.e. generalization of the results is based on rather small number of publications. Although the total number of papers was 145 in the end only one third (51) was included into the actual review. This shows that the topic is still evolving and as such, generalizations might still be premature. Reliability of the work is also partly supported by the Systematic literature Review process as other researchers may repeat the study by using the same search queries. The analysis of the collected data may differ depending how for example emphasized skills and learning outcomes would be grouped.

\section{Conclusion}

This paper has been studying the use of "code camps" and "hackathons" in software engineering and computer science education. We performed a systematic literature review utilizing Web of Science database to find out how these intensive collaborative events have been reported in academic literature. The 
search queries led to an identification of 145 papers. Out of 145 papers, 51 papers were included for final analysis based on inclusion and exclusion criteria). These papers were analyzed to find out what kind of structures were used in these events, what kind of skills and competencies were emphasized and if these events were linked to the curriculum of the universities. Analysis of the studies revealed that although these events are highly praised their links to actual educational activities are still very scarce. We believe these events can have a role in education, not necessarily replacing traditional capstone projects but to support them.

\section{REFERENCES}

[1] Joint Task Force on Computing Curricula IEEE Computer Society Association for Computing Machinery, "Software Engineering 2014: Curriculum Guidelines for Undergraduate Degree Programs in Software Engineering," Jt. Task Force Comput. Curricula IEEE Comput. Soc. Assoc. Comput. Mach., no. February, p. 134, 2014.

[2] A. for C. M. (ACM) and I. C. S. The Joint Task Force on Computing Curricula, Computer Science Curricula 2013: Curriculum Guidelines for Undergraduate Degree Programs in Computer Science. ACM, Inc, 2013.

[3] D. Delgado, A. Velasco, J. Aponte, and A. Marcus, "Evolving a Project-Based Software Engineering Course: A Case Study," in 2017 IEEE 30th Conference on Software Engineering Education and Training (CSEE\&T), 2017, vol. 2017-Janua, pp. 77-86.

[4] M. Palacin-Silva, J. Khakurel, A. Happonen, T. Hynninen, and J. Porras, "Infusing Design Thinking into a Software Engineering Capstone Course," in 2017 IEEE 30th Conference on Software Engineering Education and Training (CSEE\&T), 2017, pp. 212-221.

[5] R. Simpson and T. Storer, "Experimenting with Realism in Software Engineering Team Projects: An Experience Report," in 2017 IEEE 30th Conference on Software Engineering Education and Training (CSEE\&T), 2017, vol. 2017-Janua, pp. 87-96.

[6] B. Kitchenham, O. Pearl Brereton, D. Budgen, M. Turner, J. Bailey, and S. Linkman, "Systematic literature reviews in software engineering - A systematic literature review," Inf. Softw. Technol., vol. 51, no. 1, pp. 7-15, Jan. 2009.

[7] A. Kitchenham, "Guidelines for performing Systematic Literature Reviews in software engineering version 2.3, EBSE Technical Report, Keele Univerisity and University of Durham," Jan. 2007.

[8] A. Knutas, A. Hajikhani, J. Salminen, J. Ikonen, and J. Porras, "Cloud-based bibliometric analysis service for systematic mapping studies," ACM Int. Conf. Proceeding Ser., vol. 1008, no. 212, pp. 184
$191,2015$.

[9] G. Briscoe and C. Mulligan, "Digital Innovation: The Hackathon Phenomenon," Creat. London, no. 6, pp. 1-13, 2014.

[10] M. Komssi, D. Pichlis, M. Raatikainen, K. Kindstrom, and J. Jarvinen, "What are Hackathons for?," IEEE Softw., vol. 32, no. 5, pp. 60-67, Sep. 2015.

[11] J. Khakurel, H. Melkas, and J. Porras, "Tapping into the wearable device revolution in the work environment: a systematic review," Inf. Technol. People, vol. 31, no. 3, pp. 791-818, Jun. 2018.

[12] D. M. Blei, B. B. Edu, A. Y. Ng, A. S. Edu, M. I. Jordan, and J. B. Edu, "Latent Dirichlet Allocation," CrossRef List. Deleted DOIs, vol. 1, pp. 993-1022, 2000.

[13] D. Blei, L. Carin, and D. Dunson, "Probabilistic topic models," IEEE Signal Process. Mag., vol. 27, no. 6 , pp. 55-65, 2010.

[14] B. Penzenstadler, V. Bauer, C. Calero, and X. Franch, "Sustainability in Software Engineering: A Systematic Literature Review," in 16th International Conference on Evaluation \& Assessment in Software Engineering, 2012, pp. 3241.

[15] C. Wang and D. M. Blei, "Collaborative topic modeling for recommending scientific articles," in Proceedings of the 17th ACM SIGKDD international conference on Knowledge discovery and data mining - KDD '11, 2011, p. 448.

[16] R. R. Bond, M. D. Mulvenna, D. D. Finlay, and S. Martin, "Multi-faceted informatics system for digitising and streamlining the reablement care model," J. Biomed. Inform., vol. 56, pp. 30-41, Aug. 2015.

[17] G. Mulholland and B. Meredig, "Hackathon aims to solve materials problems," MRS Bull., vol. 40, no. 4, pp. 366-370, Apr. 2015.

[18] B. Rosell, S. Kumar, and J. Shepherd, "Unleashing innovation through internal hackathons," in Digest of Technical Papers - InnoTek 2014: 2014 IEEE Innovations in Technology Conference, 2014.

[19] S. Shiramatsu, T. Tossavainen, T. Ozono, and T. Shintani, "Towards Continuous Collaboration on Civic Tech Projects: Use Cases of a Goal Sharing System Based on Linked Open Data," in Lecture Notes in Computer Science (including subseries Lecture Notes in Artificial Intelligence and Lecture Notes in Bioinformatics), vol. 9249, 2015, pp. 8192.

[20] R. C. Craddock et al., "Brainhack: a collaborative workshop for the open neuroscience community," Gigascience, vol. 5, no. 1, p. 16, Dec. 2016.

[21] D. Cobham, C. Gowen, K. Jacques, J. Laurel, and S. Ringham, "FROM APPFEST TO ENTREPRENEURS: USING A HACKATHON EVENT TO SEED A UNIVERSITY STUDENTLED ENTERPRISE,” 2017, pp. 522-529.

[22] P. J. Robinson and P. A. Johnson, "Civic Hackathons: New Terrain for Local GovernmentCitizen Interaction?," Urban Plan., vol. 1, no. 2, p. 
65,2016

[23] J. Aboab et al., "REPRODUCIBILITY A ' datathon "model to support cross-disciplinary collaboration," pp. $1-6$.

[24] T. Tossavainen, S. Shiramatsu, T. Ozono, and T. Shintani, "A linked open data based system utilizing structured open innovation process for addressing collaboratively public concerns in regional societies," Appl. Intell., vol. 44, no. 1, pp. 196-207, 2016.

[25] B. Safarova, E. Ledesma, G. Luhan, S. Caffey, and C. Giusti, "Learning from Collaborative Integration The Hackathon as Design Charrette," vol. 2, pp. 233-240, 2013.

[26] D. Mimno, H. M. Wallach, E. Talley, M. Leenders, and A. McCallum, "Optimizing semantic coherence in topic models," in Proceedings of the 2011 Conference on Empirical Methods in Natural Language Processing, 2011, no. 2, pp. 262-272.

[27] F. Page and Sweeney Sylvester, "THE USE OF THE 'HACKATHON' IN DESIGN EDUCATION: AN OPPORTUNISTIC EXPLORATION.," in International conference on engineering and product design education, 2016, pp. 1-6.

[28] M. Alba, M. Avalos, C. Guzmán, and V. M. Larios, "Synergy between smart cities' hackathons and living labs as a vehicle for accelerating tangible innovations on cities," IEEE 2nd Int. Smart Cities Conf. Improv. Citizens Qual. Life, ISC2 2016 Proc., pp. 1-6, 2016.

[29] A. Dainotti, U. C. S. Diego, and E. Katz-bassett, "The BGP Hackathon 2016 Report," no. November 2015, 2016.

[30] A. Pathanasethpong et al., "Tackling Regional Public Health Issues Using Mobile Health Technology: Event Report of an mHealth Hackathon in Thailand," JMIR mHealth uHealth, vol. 5, no. 10, p. e155, 2017.

[31] J. Karlsen and A. S. Løvlie, "'You can dance your prototype if you like': independent filmmakers adapting the hackathon," Digit. Creat., vol. 28, no. 3, pp. 224-239, 2017.

[32] N. Birbeck, S. Lawson, K. Morrissey, T. Rapley, and P. Olivier, "Self Harmony: rethinking hackathons to design and critique digital technologies for those affected by self-harm," CHI '17 Proc. 2017 CHI Conf. Hum. Factors Comput. Syst., pp. 146-157, 2017.

[33] M. Raatikainen, M. Komssi, V. Dal Bianco, K. Kindstom, and J. Jarvinen, "Industrial experiences of organizing a hackathon to assess a device-centric cloud ecosystem," in Proceedings - International Computer Software and Applications Conference, 2013, pp. 790-799.

[34] T. Kapur et al., "Increasing the impact of medical image computing using community-based openaccess hackathons: The NA-MIC and 3D Slicer experience," Medical Image Analysis, vol. 33, pp.
176-180, 2016

[35] K. Heikkinen, J. Porras, and J. Ikonen, "Introducing code camp process," in IMSCI 2008 - 2nd International Multi-Conference on Society, Cybernetics and Informatics, Proceedings, 2008, vol. 2, pp. 175-180.

[36] T. Kilamo et al., "Knowledge transfer in collaborative teams: experiences from a two-week code camp," Companion Proc. 36th Int. Conf. Softw. Eng. - ICSE Companion 2014, pp. 264-271, 2014.

[37] J. Porras, K. Heikkinen, and J. Ikonen, "Teaching .NET programming with code camp approach," in IMSCI 2008 - 2nd International Multi-Conference on Society, Cybernetics and Informatics, Proceedings, 2008, vol. 3.

[38] A. Decker, K. Eiselt, and K. Voll, "Understanding and improving the culture of hackathons: Think global hack local," in Proceedings - Frontiers in Education Conference, FIE, 2015, vol. 2014.

[39] D. Ward, J. Hahn, and L. Mestre, "Adventure Code Camp: Library Mobile Design in the Backcountry," Inf. Technol. Libr., vol. 33, no. 3, p. 45, Sep. 2014.

[40] M. P. Lyndon et al., "Hacking Hackathons: Preparing the next generation for the multidisciplinary world of healthcare technology," Int. J. Med. Inform., vol. 112, no. December 2017, pp. 1-5, 2018.

[41] N. Linnell, S. Figueira, N. Chintala, L. Falzarano, and V. Ciancio, "Hack for the homeless: A humanitarian technology hackathon," in Proceedings of the 4th IEEE Global Humanitarian Technology Conference, GHTC 2014, 2014, pp. 577-584.

[42] T. D. Aungst, "Using a Hackathon for Interprofessional Health Education Opportunities," J. Med. Syst., vol. 39, no. 5, pp. 1-2, 2015.

[43] S. Alaoutinen, K. Heikkinen, and J. Porras, "Experiences of learning styles in an intensive collaborative course," Int. J. Technol. Des. Educ., vol. 22, no. 1, pp. 25-49, Feb. 2012.

[44] S. Zaaijer et al., "Using mobile sequencers in an academic classroom," Elife, vol. 5, no. APRIL2016, pp. 1-9, 2016.

[45] J. Tandon, R. Akhavian, M. Gumina, and N. Pakpour, "CSU East Bay Hack Day: A University hackathon to combat malaria and zika with drones," IEEE Glob. Eng. Educ. Conf. EDUCON, no. April, pp. 985-989, 2017.

[46] C. Guerrero, M. Del Mar Leza, Y. González, and A. Jaume-I-Capó, "Analysis of the results of a hackathon in the context of service-learning involving students and professionals," in 2016 International Symposium on Computers in Education, SIIE 2016: Learning Analytics Technologies, 2016. 


\section{APPENDIX 1:}

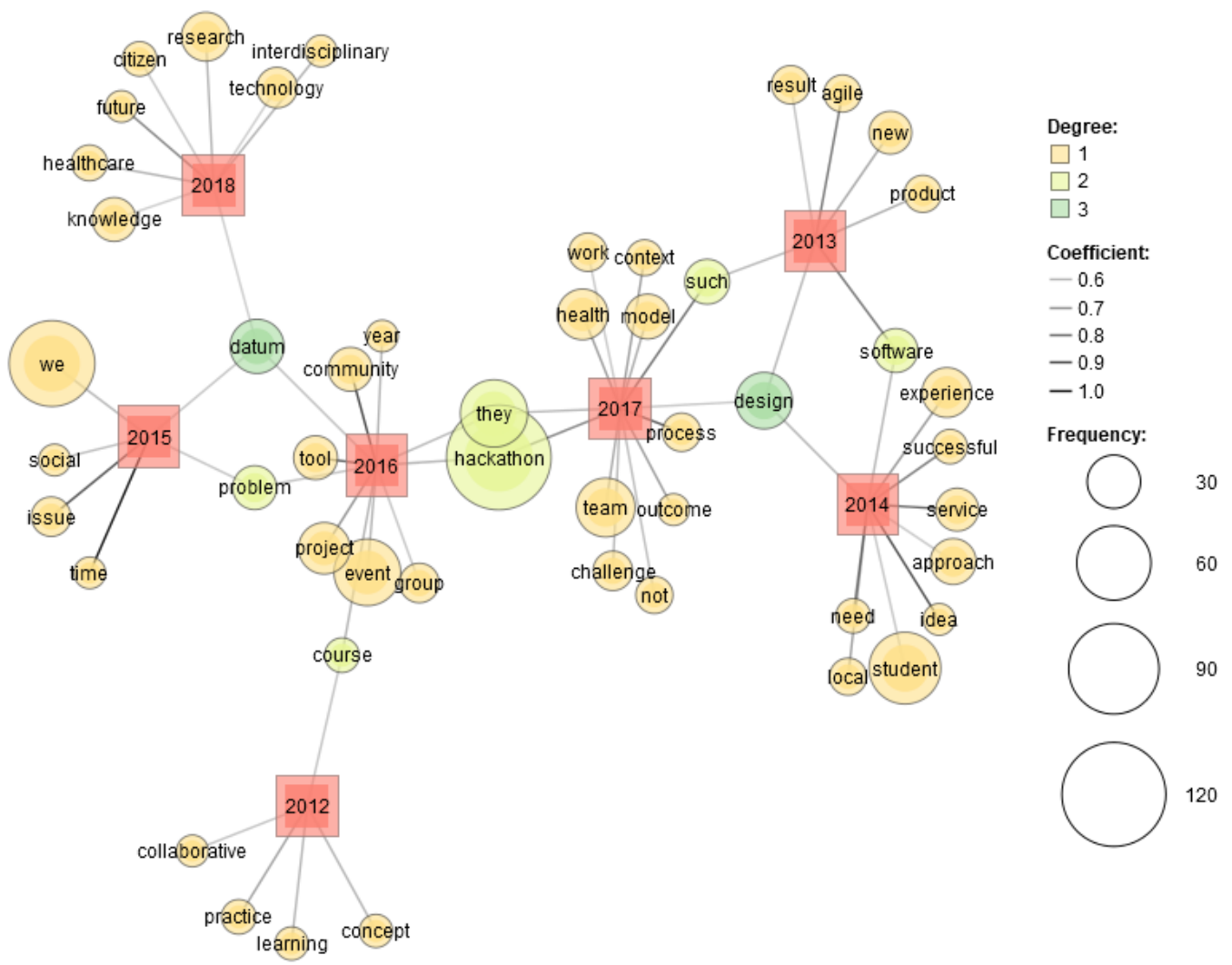

Figure A.1. Analysis of the development of the hackathon events 2012-2018 by using KHcoder
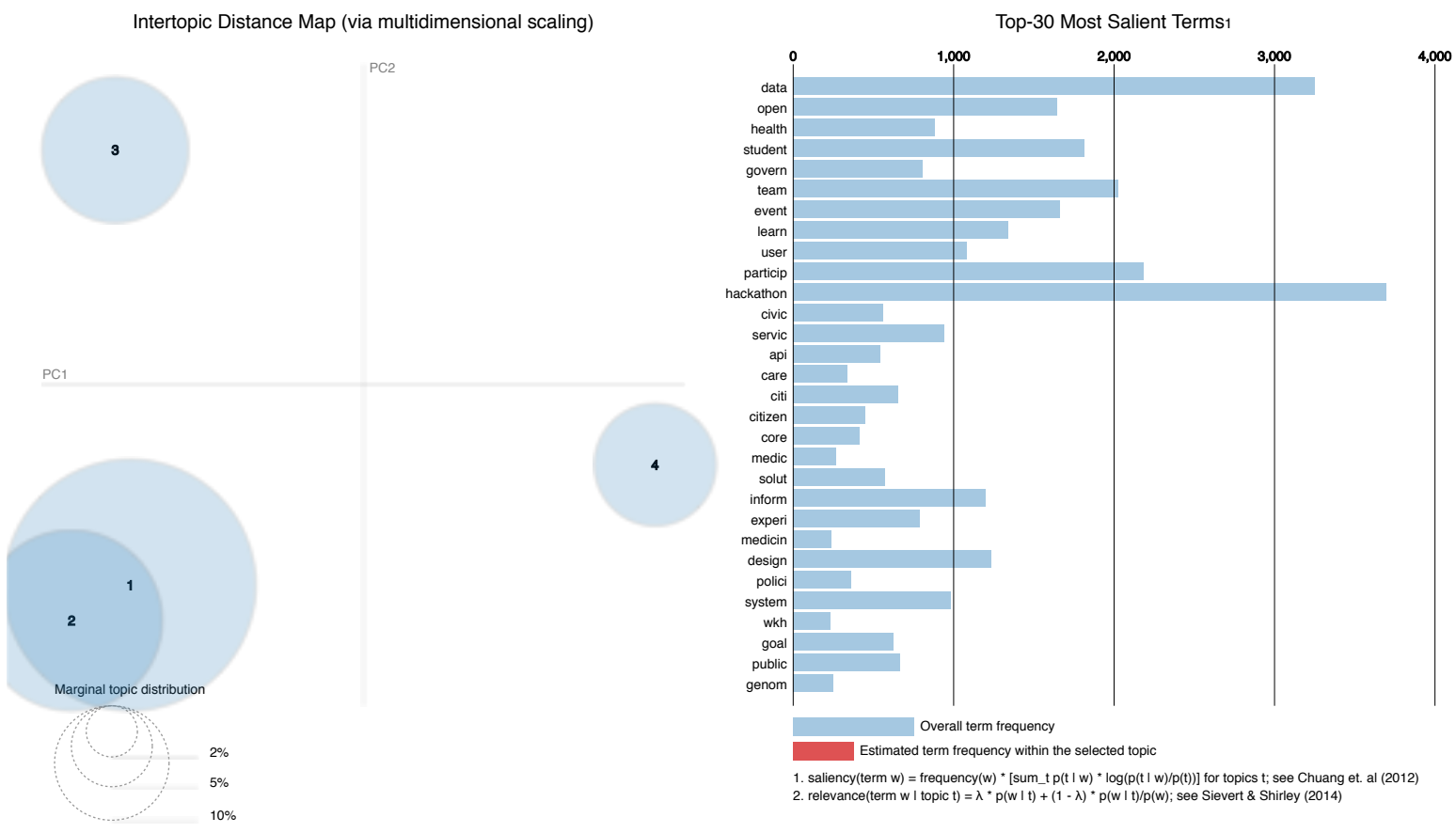

Figure A.2 Topic modeling of the hackathon related papers in our systematic literature review 